\title{
O ACESSO ÀS POLÍTICAS PÚBLICAS NO SEMIÁRIDO E SEU REFLEXO NA HETEROGENEIDADE DA AGRICULTURA FAMILIAR: O PNAE EM BOQUIRA-BA
}

\author{
Álvaro Antônio Xavier de Andrade ${ }^{1}$ \\ Gustavo Bianch Silva ${ }^{2}$ \\ Nadir Alves Xavier de Andrade ${ }^{3}$
}

\begin{abstract}
Resumo
Este artigo tem por objetivo identificar e avaliar a implementação do Programa Nacional de Alimentação Escolar (PNAE), em Boquira, semiárido baiano, além de retratar os sistemas produtivos dos agricultores que acessam esse programa. Pretende-se mostrar a relação desses sistemas com a heterogeneidade da agricultura familiar brasileira e sua influência no acesso às políticas públicas. $O$ levantamento dos dados foi feito por pesquisas bibliográficas, documentais e de campo. A pesquisa de campo teve a participação de $90 \%$ dos agricultores que comercializam via PNAE em Boquira, do secretário municipal de educação e da nutricionista responsável por elaborar os cardápios da merenda escolar. Foi identificado ser íntima a relação do pouco acesso que os agricultores familiares de Boquira têm às políticas públicas, em especial o PNAE, com a heterogeneidade da agricultura familiar brasileira.
\end{abstract}

Palavras Chaves: agricultores familiares; alimentação escolar; diversidades; recursos.

\section{THE ACCESS TO PUBLIC POLICY IN THE SEMIARID REGION AND ITS EFFECT ON FAMILY FARMING HETEROGEINITY: PNAE IN BOQUIRA-BA}

\begin{abstract}
:
This study aims to identify and evaluate the Implementation of National Program of School Feeding (PNAE) in Boquira, Bahia semiarid, as well as, to build a picture of the production systems of farmers that have been accessing this program. It intends to show the relation of these systems with the heterogeneity of the Brazilian family farming and its influence on access to public policy. Data collection was carried out through search on literature and documents, and conducting field interviews. The interviews were made with $90 \%$ of farmers that commercialize through PNAE in

\footnotetext{
${ }^{1}$ Graduado em Agronomia (UNEB). Especialização em Planejamento Ambiental com Ênfase em Educação Ambiental (UNYAHNA). Mestrado em Extensão Rural (UFV). Bolsista CNPq/UFMG/UFJF, projeto Núcleo de Extensão em Desenvolvimento Territorial do Leste e Nordeste de Minas Gerais. E-mail: aaxandrade2@hotmail.com

${ }^{2}$ Graduado em História (UFV). Mestrado em Extensão Rural (UFV). Doutorando em História (UFMG). E-mail: gbianch@gmail.com

${ }_{3}^{3}$ Graduada em Letras e Literaturas de Língua Portuguesa (UNEB). Especialização em Estudos Linguísticos e Produção de Textos (UNEB). Professora aposentada. E-mail: nandrade6@gmail.com
} 
Boquira, with the Municipal Secretary of Education, and the Nutritionist responsible for preparing the school lunch menus. It was identified a close relation between the unusual acess to public politcs, especially PNAE, by the family farmers of Boquira, with the heterogeneity of family farming of Brazil.

Keywords: Diversities; family farmers; resources; school feeding

\section{INTRODUÇÃO}

A agricultura familiar recebe destaque no cenário brasileiro, principalmente por ser lembrada pela capacidade de absorção de mão de obra e pela produção de alimentos, sobretudo para o autoconsumo e para o abastecimento do mercado interno. Entretanto, é necessário destacar que, além de colaborar para a redução do êxodo rural e constituir principal fonte de recursos financeiros para as famílias de menor renda no campo, a agricultura familiar contribui, de forma expressiva, para a geração da riqueza do país (GUILHOTO et al., 2012).

Segundo o Ministério do Desenvolvimento Agrário (MDA), o Censo Agropecuário 2006, feito pelo Instituto Brasileiro de Geografia e Estatística (IBGE) mostrou que a agricultura familiar é responsável por $38 \%$ do Valor Bruto de Produção (VBP) do setor primário brasileiro. O VBP por hectare desse setor gira em torno de $R \$ 677,00$, superior em $89 \%$ ao da agricultura patronal, que é de $R \$ 358,00$ por hectare. A agricultura familiar ainda é responsável por $74,4 \%$ do pessoal ocupado no setor primário, aproximadamente 12,3 milhões de pessoas, possuindo $84,4 \%$ dos estabelecimentos agropecuários do país, ocupando, contudo, apenas $24,3 \%$ da área total utilizada pela agropecuária nacional (MDA, 2010).

De acordo com o documento "Perspectivas de la agricultura y del desarrolho rural em las Américas: uma mirada hacia América Latina y el Caribe", de 2014, elaborado em conjunto pela $\mathrm{CEPAL}^{4}, \mathrm{FAO}^{5}$ e $\mathrm{IICA}^{6}$, todos os estudos realizados sobre a agricultura familiar para a América Latina comprovam que existe um caráter heterogêneo neste setor, inclusive a nível de escala de acesso aos diversos recursos existentes. Assim, os agricultores familiares têm diferenças em relação à posse de terras, de capital e de recursos naturais, tendo, igualmente, diferentes possibilidades de acesso a bens e a serviços públicos, fato que resulta em heterogeneidade também na capacidade de inovar e alterar seus sistemas de produção, de inserir-se nos mercados, de reformular as estratégias de trabalho e de diversificação de produtos, no intuito de aumentar a geração de renda.

Essa heterogeneidade da agricultura familiar, no Brasil, é destacada por alguns autores, entre os quais, Souza Filho et al. (2004). Segundo esses autores, a agricultura familiar brasileira engloba os agricultores extremamente pobres que possuem uma pequena propriedade, em que, com muita dificuldade, desenvolvem atividades na busca do sustento para suas famílias. Por outro lado, também estão incluídos os agricultores que possuem diversos recursos, sejam eles, terra, capital, organização ou conhecimento especializado. Existe uma série de elementos que evidenciam essa heterogeneidade, entre os quais os autores citam: orientação

\footnotetext{
${ }^{4}$ Comissão Econômica para América Latina e Caribe.

${ }^{5}$ Organização das Nações Unidas para Alimentação e Agricultura.

${ }^{6}$ Instituto Interamericano de Cooperação para Agricultura.
} 
técnica ${ }^{7}$, utilização de energia elétrica, de adubos, de técnicas de conservação dos solos e tipos de força utilizada nos trabalhos.

Na mesma linha de estudos sobre a heterogeneidade da agricultura familiar brasileira, Schneider e Niederle (2008) descrevem que existem diversas formas de se realizar, ou se "fazer a agricultura". Essas formas, segundo esses autores, variam de acordo com alguns caracteres, entre eles, contextos sociais, interação das famílias com os ecossistemas e a origem histórica dessas famílias.

Dessa forma, parte-se do pressuposto de que a heterogeneidade, associada a um profundo desnível socioeconômico e as diferentes interações humanas nos diversos ecossistemas brasileiros, refletem nas realidades encontradas, diferenciando os resultados da implementação e da operacionalização das políticas públicas de caráter universal. Assim, essas distintas realidades são responsáveis pela interferência e/ou pela dificuldade encontrada pelos agricultores familiares para acessar os recursos existentes, principalmente nas regiões mais pobres, como o semiárido brasileiro.

Diante desse cenário, este trabalho pretende analisar como o Programa Nacional de Alimentação Escolar (PNAE) ${ }^{8}$ tem sido implementado no município de Boquira, região da Chapada Diamantina, semiárido baiano. Além dos elementos trazidos por Souza Filho et al. (2004), que podem potencializar os sistemas produtivos, existem na região estudada graves problemas relacionados à pobreza e a dificuldades na obtenção da produção primária, causados, principalmente, pelas características edafoclimáticas da região, em especial a escassez hídrica. Esses problemas e dificuldades se alinham, então, aos caracteres trazidos por Schneider e Niederle (2008) como também sendo responsáveis pela existência da heterogeneidade da agricultura familiar brasileira.

Nesse contexto, para fazer uma análise do PNAE em Boquira, buscou-se ainda construir um retrato do modo de reprodução social e dos sistemas produtivos dos agricultores que acessam esse programa. Dessa forma, objetiva-se identificar a presença dos elementos trazidos por Souza Filho et al. (2004), que confirmam a existência da heterogeneidade da agricultura familiar brasileira e que tanto podem potencializar a produção agrícola, quanto podem colaborar no acesso às políticas públicas. Também, pretende-se interpretar algumas características trazidas pelo Censo Agropecuário 2006, que serão apresentadas como alicerce para evidenciar essa heterogeneidade.

Assim, partindo do pressuposto de que as diferentes realidades regionais, expostas por meio da heterogeneidade da agricultura familiar brasileira, influenciam no acesso às políticas públicas, esse artigo pretende responder à seguinte indagação: existe em Boquira potencialização dos sistemas produtivos primários, por meio do acesso aos recursos existentes no país, de tal forma que a produção seja contínua e diversificada, colaborando com a comercialização via PNAE?

Para alcançar seus objetivos, o artigo está estruturado em oito seções, incluindo a introdução e as considerações finais. Na segunda seção, serão descritas

\footnotetext{
${ }^{7}$ Nesse artigo, a expressão "orientação técnica" será substituída pelo termo assistência técnica e extensão rural (Ater), por se entender que esse conceitua melhor o atual modelo para esses serviços no país, inclusive retratado pela Política Nacional de Assistência Técnica e Extensão Rural (PNATER), aprovada em 2010 e que deve nortear os trabalhos de Ater.

${ }^{8}$ A escolha dessa política pública justifica-se pelo fato de ser a mais longeva do país. Aliado a isso, considera-se que a comercialização é um dos gargalos que devem ser superados para o fortalecimento da agricultura familiar brasileira.
} 
algumas informações sobre o município de Boquira. Na terceira, será exposta uma breve discussão sobre a complexidade que envolve a implementação de políticas públicas universais em diferentes contextos locais. Na quarta, serão analisadas a origem e as características do PNAE, que fizeram deste programa a política pública considerada de maior longevidade no Brasil. A quinta seção apresenta a metodologia utilizada. $\mathrm{Na}$ sexta, serão expostos alguns dados do Censo Agropecuário 2006 relacionados à heterogeneidade da agricultura família. A sétima é subdividida em três partes: a primeira apresenta algumas considerações sobre os rendimentos financeiros da agropecuária em Boquira; na segunda, será exposta uma breve caracterização dos sistemas produtivos dos agricultores que comercializam via PNAE e suas perspectivas sobre o programa; por fim, na terceira parte, será descrita a perspectiva dos gestores municipais, responsáveis pelo PNAE, quanto à operacionalização desse programa no município.

\section{CARACTERÍSTICAS SOCIOECONÔMICAS ATUAIS DO MUNICÍPIO DE BOQUIRA}

O município de Boquira dista $655 \mathrm{~km}$ da capital do estado, Salvador, e está localizado na região denominada Chapada Diamantina, semiárido baiano. Tem área de $1.482,651 \mathrm{~km}^{2}$, população de 22.042 habitantes, clima subúmido a seco, temperatura média anual de $23,8^{\circ} \mathrm{C}$ e pluviosidade anual de 894,8 milímetros (SEI, 2011).

Em relação ao Produto Interno Bruto - PIB municipal, no ano de 2008, a indústria respondeu por $\mathrm{R} \$ 6,96$ milhões; a agropecuária, por $\mathrm{R} \$ 7,56$ milhões; e o setor de serviços, que inclui a administração pública e as atividades governamentais, por $\mathrm{R} \$ 47,88$ milhões (SEI, 2011).

Ao analisar os dados sobre o tema da pobreza no Atlas Brasil 2013 do Programa das Nações Unidas para o Desenvolvimento (PNUD), referentes ao ano de 2010 , constata-se que, aproximadamente, $27 \%$ da população era extremamente pobre $^{9}$ (6.017 habitantes); $13 \%$ era pobre ${ }^{10}$ (2.773 habitantes); $20 \%$ era vulnerável à pobreza $^{11}$ (4.435 habitantes); e $40 \%$ não estava relacionada a esse tema $(8.795$ habitantes).

A população de Boquira tem nas atividades agropecuárias a principal alternativa de emprego e renda. Segundo o Atlas Brasil (2013), os principais setores de trabalho estão assim divididos para a ocupação dos maiores de 18 anos: 0,42\% no setor extrativo mineral; $2,65 \%$ na indústria de transformação; 3,67 em outros setores; $9,51 \%$ na construção; $10,77 \%$ no comércio; $28,15 \%$ no setor de serviços; e $44,83 \%$ no setor agropecuário.

Ainda, no tocante à empregabilidade aplicada ao setor primário em Boquira, segundo o IBGE, existem no município 2.914 estabelecimentos da agricultura familiar (95,8\%), enquanto os patronais são apenas 128 (4,2\%). Em média, os estabelecimentos familiares têm área de 12,5 hectares, e os patronais, de 239,5 hectares, ressaltando-se que o módulo fiscal para o município é de 65 hectares. Esses dados mostram a importância da agricultura familiar para o município e, consequentemente, a urgência de políticas públicas destinadas ao fortalecimento deste setor, a exemplo do PNAE.

\footnotetext{
${ }^{9}$ Indivíduos com renda domiciliar per capita igual ou inferior a $\mathrm{R} \$ 70,00$ mensais em agosto de 2010. O universo de indivíduos é limitado àqueles que vivem em domicílios particulares permanentes (PNUD 2013).

${ }_{10}$ Idem, porém com renda per capita de $\mathrm{R} \$ 140,00$.

${ }^{11}$ Idem, porém com renda per capita $\mathrm{R} \$ 255,00$.
} 


\section{A IMPLEMENTAÇÃo DE POLítICAS PÚBLICAS UNIVERSAIS EM CONTEXTOS LOCAIS}

Neste tópico, pretende-se apresentar uma breve discussão que aborda a questão das políticas públicas no Brasil. Assim, o objetivo desta iniciativa é fornecer subsídios para entender a complexidade que envolve a implementação e a operacionalização de políticas públicas universais, como o PNAE, em contextos locais.

Segundo Souza (2007), o âmbito das políticas públicas traz à tona uma importante questão: qual o papel dos governos na definição e na implementação das políticas públicas? Para a autora, as ações governamentais não são apenas resultado das pressões de grupos de interesses, tampouco podem ser expressas apenas pelas decisões daqueles que estão no poder, como também não representam somente os interesses de "determinadas" classes sociais. Para ela, no mundo contemporâneo, o Estado tem certa autonomia, espaço próprio, mas não deixa de ser influenciado por fatores internos e externos. Logo, os governos, utilizando-se desta autonomia e de suas capacidades, podem criar condições para que as políticas públicas possam atingir seus objetivos.

Para Anjos \& Caldas, de uma maneira bastante simples, política pública é "um meio através do qual o Estado intervém para operar o ordenamento hierárquico de alternativas e interesses que manifestam os diferentes setores e grupos que conformam as sociedades contemporâneas" (ANJOS; CALDAS, 2007, p. 154). No entendimento de Dias, políticas públicas "são as ações empreendidas ou não pelos governos, que deveriam estabelecer condições para que todos possam atingir uma melhoria da qualidade de vida compatível com a dignidade humana" (DIAS, 2012, p. 12).

Outro aspecto importante a se considerar sobre uma política pública é a cooperação entre os atores envolvidos no seu âmbito. Em ambientes de cooperação, a política pública tende a ser de melhor qualidade, menos sensível a embates políticos; porém, em ambientes de difícil cooperação, a mesma política tende a ser instável, sujeitando-se a questões políticas, e quiçá, a uma coordenação de qualidade duvidosa, que acarretará dificuldades em sua operacionalização (STEIN; TOMMASI, 2006a).

Essas características, aliadas a estudos sobre políticas públicas e contextos locais, como os de Tonneau \& Sabourin (2007), os quais consideram que os resultados e os impactos das políticas públicas voltadas à agricultura familiar apresentam em diferentes regiões uma grande variabilidade, mostram a importância do estudo ora apresentado. Para os autores citados, esta variabilidade estaria ligada a dois tipos de fatores. O primeiro diz respeito àqueles que dependem do documento das políticas públicas, estando diretamente ligados à qualidade, ao conteúdo do texto, além das formas que o documento traz para que ocorra sua operacionalização. O segundo diz respeito às capacidades que provêm dos atores locais envolvidos na operacionalização da política pública, ou seja, a capacidade de mobilizar a participação visando o fortalecimento social e promovendo a adequação da política pública às realidades locais.

Dessa forma, o processo de implementação de políticas públicas em contextos locais é marcado pela dificuldade de serem ajustados, em uma regra 
geral, os elementos singulares das diferentes realidades em que elas serão aplicadas.

A eficiência das políticas públicas está diretamente ligada à maneira como elas são discutidas, aplicadas e operacionalizadas. Parte-se da premissa de que estes três itens são tão importantes quanto o próprio conteúdo específico do documento que rege a política, podendo ter menor relevância quando a abordagem utilizada para a formulação da política é estritamente tecnocrática. Desta maneira, poderá haver fracasso dos objetivos propostos e frustração das expectativas que giram em torno de uma determinada política pública (STEIN; TOMMASI, 2006b).

Assim, o êxito de uma política pública não pode ser esperado com base apenas em seus atributos teóricos, ou seja, na qualidade do documento desta política. Julga-se também necessária a consideração dos contextos sociais, políticos e institucionais, a que esta política será submetida. Considerando esses argumentos, diferentes contextos podem apresentar diferenças na implementação e operacionalização de uma mesma política.

Dessa forma, o PNAE, por apresentar um único documento para todo o país, o que significa a padronização da forma como ele deve ser implementado e operacionalizado, é caracterizado como uma política universal. Entretanto, em diferentes contextos locais e em seus conjuntos de particularidades (questões sociais, econômicas, políticas, culturais, tradicionais, ambientais, institucionais etc.), a operacionalização do PNAE, ou de outras políticas públicas, pode ocorrer de forma diferenciada ou encontrar entraves distintos. De maneira geral, a produção primária no semiárido fica restrita à época das chuvas. A maioria dos agricultores dessa região, por exemplo, os que acessam o PNAE em Boquira, plantam em sequeiro e não utilizam técnicas de irrigação objetivando continuidade da produção.

As políticas públicas estão, assim, expostas às formas de gestão de acordo com as instituições responsáveis por sua operacionalização. Dessa forma, a abertura de um "sistema político" está diretamente ligada ao comprometimento dos seus gestores em proporcionar ou não esta abertura (STEIN; TOMMASI, 2006b). Nesse artigo, essa abertura deve ser entendida como a organização do arranjo institucional da prefeitura de Boquira em potencializar a produção primária e mobilizar os agricultores familiares do município para que possam ter acesso às políticas públicas voltadas para o setor, a exemplo do PNAE.

Tem-se, assim, a existência de um mecanismo burocrático pautado na busca de interesses distintos pelas instituições ou por seus responsáveis, o qual pode estar ligado à inércia dessas instituições em dar sentido prático a determinada política pública. Além disso, os potenciais beneficiários podem ter diversas dificuldades, ou até mesmo desconhecer a existência de políticas públicas; fato que pode acarretar o desinteresse desses beneficiários em relação à participação nos processos que envolvem essas políticas. Portanto, um contexto local e suas particularidades podem influenciar a implementação e a operacionalização dos programas e políticas públicas (FLEXOR; LEITE, 2006).

Dessa forma, as políticas públicas são avaliadas no intuito de serem obtidos melhores resultados. Para Secchi (2010), "a avaliação é a fase do ciclo de políticas públicas em que o processo de implementação e o desempenho da política são examinados com o objetivo de conhecer melhor o estado da política e o nível de redução do problema que a gerou" (SECCHI, 2010, p. 49). Assim, a avaliação tem o intuito de melhorar a política pública, partindo do pressuposto de que essa avaliação pode aumentar o conhecimento que os atores políticos têm dessa política, 
permitindo assim uma comparação da sua funcionalidade em diferentes contextos locais.

\section{O PROGRAMA NACIONAL DE ALIMENTAÇÃO ESCOLAR (PNAE)}

Entre as políticas públicas brasileiras, o Programa Nacional de Alimentação Escolar (PNAE) se destaca como alternativa de combate à fome e à desnutrição, problemas graves de saúde pública no Brasil, sendo considerada a política pública de maior longevidade do país (PEIXINHO, 2013; SARAIVA et al., 2013). Porém, antes da oficialização desse programa, outras ações públicas foram tomadas para amenizar ou resolver os problemas alimentares brasileiros.

O início das providências governamentais para minimizar as péssimas condições de alimentação no país ocorre em 1930. Porém, é em 1955 que surge a Campanha Nacional da Merenda Escolar, que recebia auxílio internacional (PEIXINHO, 2013). Nessa mesma década, a FAO teve como Presidente do Conselho Executivo Josué de Castro, deputado federal brasileiro que contribuiu, consideravelmente, para a conscientização mundial da necessidade de projetos direcionados à erradicação da fome. De 1955 até 1970, o programa "Alimentos para a Paz", da Organização das Nações Unidas (ONU), foi acionado para colaborar na erradicação da fome no Brasil. Mantimentos vindos dos Estados Unidos, que uniram ajuda externa à necessidade de escoar excedentes, formaram parte significativa da alimentação escolar. Até 1970, organizações internacionais eram predominantes neste setor (MALUF, 2009; PEIXINHO, 2013; REAL; SCHNEIDER, 2011).

O governo federal responsabilizou-se, então, pela estruturação de um programa nacional de alimentação que buscasse contemplar a população escolar. Porém, efetivamente, esse programa não atendia à necessidade nutricional dos estudantes e não valorizava os hábitos alimentares locais nem os cultivos dos agricultores das mais diferentes regiões do Brasil. Foi assim que o Programa de Alimentação Escolar foi formalizado no Ministério da Educação e Cultura por meio do decreto $n^{\circ} 37$. 106, de 1955. De início, o programa atendia apenas os alunos do ensino fundamental, incluindo creches e pré-escolas (MALUF, 2009; PEIXINHO, 2013; TURPIN, 2009).

A partir da década de 1970, várias empresas nacionais passaram a ser fornecedoras de alimentos para o governo federal. Com o projeto da Campanha Nacional de Alimentação Escolar, incluída no II Programa Nacional da Alimentação e Nutrição, os alunos da pré-escola e aqueles matriculados no ensino fundamental das escolas públicas passaram a receber uma refeição que atendia a $15 \%$ do valor nutricional recomendado para a alimentação diária durante o ano letivo (PEIXINHO, 2013).

Somente em 1979, o programa adquiriu a nomenclatura atual, Programa Nacional de Alimentação Escolar (PNAE). Inicialmente, a administração do programa era centralizada, tendo o governo federal como único responsável por sua operacionalização. A descentralização veio ocorrer no ano de 1994 pela Lei $n^{\circ}$ 8.913, considerada um grande avanço do programa, pois possibilitou melhoras na logística e significou redução dos custos na distribuição dos alimentos. Permitiu também que a compra fosse feita com base nos hábitos alimentares regionais, possibilitando aos comerciantes locais e pequenos produtores agropecuários serem ser inseridos no programa (PEIXINHO, 2013; SARAIVA et al., 2013). 
No histórico do PNAE, vários princípios nortearam a evolução do programa, considerando a análise dos alimentos nutritivos que são ministrados nas creches e escolas públicas do país, o que inclui as comunidades quilombolas e indígenas. Nos cardápios elaborados, é obrigatória a inclusão de frutas e hortaliças. O programa exclui o oferecimento de refrigerantes, sucos em pó, alimentos com alto teor de sal, gordura e açúcar, com o objetivo de diminuir o número de futuros obesos, diabéticos e hipertensos, entre outras patologias (PEIXINHO, 2013; REAL; SCHNEIDER, 2011).

Na esteira das melhorias do programa, a publicação da Lei no 11.947, de 16 de junho de 2009, ampliou os beneficiários. A restrição ao ensino fundamental foi superada, passando a fazer parte do PNAE todos os alunos da educação básica, a qual engloba a educação infantil, ensino fundamental, ensino médio e o programa de Educação de Jovens e Adultos (SARAIVA et al., 2013).

A aplicação dos recursos, que são repassados pelo Fundo Nacional de Desenvolvimento da Educação (FNDE), é de competência das Secretarias Municipais de Educação. Essas secretarias têm a obrigatoriedade, desde 2010, de aplicar no mínimo 30\% desses recursos em alimentos oriundos da agricultura familiar, o que inclui a observância de itens como alimentos orgânicos ou agroecológicos no cardápio escolar. Assim, o PNAE, além de visar à melhoria da saúde pública, busca a abertura de mercados para a agricultura familiar.

É importante citar também a atuação dos nutricionistas no programa. A eles cabe o relevante papel de orientação alimentar, o que prioriza a nutrição e a saúde dos estudantes, além da função de regionalização dos cardápios, ou seja, adaptálos às realidades culturais e às produções locais.

\section{PROCEDIMENTOS METODOLÓGICOS}

O levantamento dos dados teve por base pesquisas bibliográficas, documentais e de campo. A pesquisa de campo foi do tipo quantitativo-descritiva, com aplicação de questionários e formulários a indivíduos envolvidos no âmbito do PNAE em Boquira.

Para comprovar a diversidade dos sistemas produtivos da agricultura familiar no Brasil, foram feitos recortes de alguns dados do Censo Agropecuário 2006, apresentados nas tabelas que seguem. Assim, foi elaborado um quadro comparativo com esses dados, que envolvem e caracterizam esses sistemas produtivos. Para a análise, utilizou-se um estado de cada região brasileira: Amazonas para a Região Norte; Mato Grosso para a Região Centro-Oeste; São Paulo para a Região Sudeste; Santa Catarina para a Região Sul; e Bahia, área do estudo de caso, representando a Região Nordeste. Esses estados foram escolhidos de forma aleatória, com exceção da Bahia, que foi escolhida com o intuito de fazer uma conexão com o município pesquisado.

Com o uso dessa metodologia, foi possível coletar informações sobre a heterogeneidade da agricultura familiar brasileira, dos rendimentos da agropecuária de Boquira, além de identificar as perspectivas dos gestores e dos agricultores familiares sobre o programa e, por fim, caracterizar os sistemas produtivos desses agricultores.

No dia 10 de dezembro de 2013, foi feita uma reunião no município com os agricultores familiares que comercializavam via PNAE, o secretário de educação e a nutricionista responsável pela elaboração dos cardápios no município. Inicialmente, houve uma explicação sobre os objetivos da pesquisa e, então, individualmente, 
foram aplicados os formulários com os agricultores, sendo esses compostos por perguntas de múltipla escolha associadas a respostas abertas. Com os demais participantes, adotou-se o questionário como técnico de coleta de dados, sendo esse composto por perguntas abertas, enviado por e-mail e recebido da mesma forma para posterior análise.

\section{O "CENSO AGROPECUÁRIO 2006" E A HETEROGENEIDADE DA AGRICULTURA FAMILIAR BRASILEIRA}

Com respaldo nos dados do censo agropecuário, pode-se observar que a agricultura familiar é responsável pela maioria dos estabelecimentos agropecuários em todos os estados analisados, com menor abrangência para São Paulo e Mato Grosso (Tabela 01).

Tabela 01 - Estabelecimentos familiares, tamanho médio, área ocupada e pessoal ocupado nos estabelecimentos familiares

\begin{tabular}{lcccc}
\hline Estados & Estabelecimentos Familiares $^{1}$ & $\begin{array}{c}\text { Tamanho } \\
\text { médio }\end{array}$ & Área ocupada $^{2}$ & $\begin{array}{c}\text { Pessoal }_{\text {ocupado }^{3}} \\
(\%)\end{array}$ \\
(ha) & $(\%)$ & $(\%)$ \\
\hline BA & 87 & 15 & 34 & 81 \\
AM & 93 & 23,9 & 41 & 91 \\
SP & 66 & 16,60 & 15 & 36 \\
MT & 76 & 56,70 & 10 & 60 \\
SC & 87 & 15,7 & 44 & 82
\end{tabular}

Fonte: Elaborado de acordo com os dados do Censo Agropecuário 2006.

1 Porcentagem dos estabelecimentos familiares em relação ao número total de estabelecimentos;

2 Porcentagem ocupada pela agricultura familiar em relação a área total ocupada pela agropecuária nos estados;

${ }^{3}$ Porcentagem do pessoal ocupado na agricultura familiar em relação ao total da mão de obra ocupada na agropecuária nos estados.

Em São Paulo, este fato se deve, principalmente, aos cultivos de cana-deaçúcar. O estado é disparado o maior produtor nacional, com aproximadamente $60,4 \%$ da produção do país, sendo que a especialização desses cultivos afasta os produtores menos capitalizados (IBGE, 2006). Consequentemente, existe concentração de terras e dos cultivos de cana nos estabelecimentos patronais, detentores de maiores recursos financeiros. Em Mato Grosso, a exemplo das outras áreas de cerrado do país, o principal motivo é a ocupação das terras com a pecuária extensiva e com a agricultura, sobretudo nos cultivos de soja, milho e algodão, caracterizados pela alta tecnificação, o que influencia diretamente na concentração das terras.

A agricultura familiar é responsável também pela maioria das ocupações do setor primário nos estados analisados, com exceção apenas de São Paulo, que tem $36 \%$. No Brasil, só o Distrito Federal tem índice menor, 29\%. Mesmo sendo responsável pela maioria dos estabelecimentos, a agricultura familiar ocupa a menor quantidade das áreas destinadas à agropecuária em todos os estados analisados, principalmente em Mato Grosso e São Paulo, tendo maior porcentagem, 44\%, no 
estado de Santa Catarina. O Amazonas se destaca com o maior índice de pessoal ocupado na agricultura familiar do país, $91 \%$.

O total de financiamentos por estado é apresentado na Tabela 02. Bahia e Santa Catarina se destacam em números absolutos, porém, a relação entre os totais de financiamentos e de estabelecimentos nesses estados é bem diferente. A Bahia tem aproximadamente $295 \%$ estabelecimentos a mais do que Santa Catarina, porém os financiamentos não chegam a ser superiores em 8,5\%.

Tabela 02 - Estabelecimentos familiares que obtiveram financiamento

\begin{tabular}{ccccc}
\hline $\begin{array}{c}\text { Total de } \\
\text { estabelecimentos no } \\
\text { estado }\end{array}$ & Total de & $\begin{array}{c}\text { Relação } \\
\text { Total de } \\
\text { financiamentos/ } \\
\text { Total de } \\
\text { estabelecimentos }\end{array}$ & $\begin{array}{c}\text { Porcentagem dos } \\
\text { estabelecimentos que } \\
\text { obtiveram } \\
\text { financiamento }\end{array}$ \\
\hline BA & 665.831 & 78.264 & 0,117 & $10,85 \%$ \\
AM & 61.843 & 2.873 & 0,046 & $4,65 \%$ \\
SP & 151.015 & 17.877 & 0,118 & $11,84 \%$ \\
MT & 86.167 & 12.343 & 0,143 & $14,32 \%$ \\
SC & 168.544 & 72.166 & 0,428 & $42,82 \%$ \\
\hline
\end{tabular}

Fonte: Elaborado de acordo com os dados do Censo Agropecuário 2006.

Pelo Valor Bruto de Produção (VBP) apresentado na Tabela 03, constata-se que a Bahia, dos estados analisados, é o que apresenta menor rendimento médio financeiro para o VBP por estabelecimento, seguida por Amazonas e Mato Grosso. Esses estados também têm os menores VBP por hectare, porém, Mato Grosso, apesar de ter o menor VBP por hectare, tem esse índice, por estabelecimento, maior do que a média do Amazonas e da Bahia. Isto ocorre porque o tamanho médio do estabelecimento familiar mato-grossense é de 56,7 hectares, no Amazonas é de 23,9 e na Bahia, de apenas 15.

Tabela 03 - Valor Bruto de Produção - VBP da agricultura familiar

\begin{tabular}{cccc}
\hline Estado & $\begin{array}{c}\text { Por } \\
\text { estabelecimento } \\
(\mathrm{R} \$)\end{array}$ & $\begin{array}{c}\text { Contribuição com VBP } \\
\text { estadual } \\
(\%)\end{array}$ & $\begin{array}{c}\text { Por hectare } \\
(\mathrm{R} \$)\end{array}$ \\
\hline BA & $5.606,50$ & 44 & 375 \\
AM & $8.715,60$ & 83 & 365 \\
SP & $26.772,10$ & 16 & 1.613 \\
MT & $12.986,40$ & 12 & 229 \\
SC & $33.680,50$ & 64 & 2.146 \\
\hline
\end{tabular}

Fonte: Elaborado de acordo com os dados do Censo Agropecuário 2006.

Neste quesito, Santa Catarina e São Paulo se destacam no cenário nacional por serem os estados de maior VBP por hectare do país. Ocupam também a segunda e terceira posição, respectivamente, na média desse índice por estabelecimento, perdendo apenas para o Distrito Federal, que tem média de $R \$$ 4.286,00. Assim, esses estados mostram maior potencial econômico dos seus sistemas produtivos. O tamanho médio dos estabelecimentos em São Paulo, Santa 
Catarina e Bahia é praticamente o mesmo, o que aponta para o menor rendimento financeiro dos estabelecimentos baianos.

As receitas oriundas de aposentadorias ou pensões e de programas dos governos são apresentados nas Tabelas 04. Bahia e Santa Catarina são os estados que têm o maior número de beneficiários de aposentadoria ou pensões, ao contrário do Amazonas, que tem o menor número. Enquanto São Paulo tem menos de $2 \%$ dos estabelecimentos assistidos pelos programas especiais dos governos, como Bolsa Família, a Bahia é o estado em que os agricultores familiares têm disparado o maior número de beneficiários desses programas, chegando a atingir mais de $18 \%$ do total dos estabelecimentos familiares baianos. Consequentemente, isso aponta para um quadro acentuado de pobreza no estado.

Tabela 04 - Outras receitas obtidas pelo agricultor familiar no ano

\begin{tabular}{|c|c|c|c|}
\hline \multirow{3}{*}{ Estados } & \multicolumn{3}{|c|}{ Aposentadorias ou pensões } \\
\hline & \multicolumn{2}{|c|}{ Estabelecimentos beneficiados no estado } & Valor \\
\hline & Unidades & $\begin{array}{c}\text { Porcentual em relação ao total do } \\
\text { estado (\%) }\end{array}$ & $\begin{array}{c}1.000 \\
\mathrm{R} \$\end{array}$ \\
\hline $\mathrm{BA}$ & 159.093 & 23,9 & 819.826 \\
\hline AM & 3.846 & 6,22 & 17.891 \\
\hline SP & 20.995 & 13,9 & 151.113 \\
\hline MT & 8.911 & 10,34 & 58.120 \\
\hline SC & 42.472 & 25,2 & 289.881 \\
\hline \multirow{3}{*}{ Estados } & \multicolumn{3}{|c|}{$\begin{array}{l}\text { Programas especiais dos governos } \\
\text { (Federal, Estadual e Municipal) }\end{array}$} \\
\hline & \multicolumn{2}{|c|}{$\begin{array}{c}\text { Estabelecimentos } \\
\text { Beneficiados no estado }\end{array}$} & Valor \\
\hline & Unidades & $\begin{array}{c}\text { Porcentual em relação ao total do } \\
\text { estado (\%) }\end{array}$ & $\begin{array}{c}1.000 \\
\mathrm{R} \$\end{array}$ \\
\hline $\mathrm{BA}$ & 121.072 & 18,2 & 95.990 \\
\hline AM & 4.471 & 7,2 & 4.622 \\
\hline SP & 2.919 & 1,9 & 4.962 \\
\hline MT & 2.710 & 3,14 & 3.956 \\
\hline SC & 10.666 & 6,3 & 14.093 \\
\hline
\end{tabular}

Fonte: Elaborado de acordo com os dados do Censo Agropecuário 2006.

\section{A AGROPECUÁRIA E O PNAE EM BOQUIRA}

\subsection{O rendimento financeiro da agropecuária em Boquira}

A alta porcentagem referente à pobreza em Boquira despertou o interesse em analisar as questões que se referem aos rendimentos agropecuários no município, uma vez que, aproximadamente, $45 \%$ da população local está ocupada nesse setor. Dados do PNUD relacionados ao total dos estabelecimentos municipais revelam que a média do VBP por estabelecimento anual é de $R \$ 2.485,20$ e a mensal, de $R \$ 207,10$, indicando baixo rendimento financeiro dos sistemas produtivos primários. Assim, utilizando-se dos dados do Censo Agropecuário, buscou-se compreender as razões de tal situação. 
Segundo o IBGE (2006), o setor agropecuário do município analisado tem como principais produtos o milho, o feijão, a mandioca, a cana-de-açúcar, a banana, o leite e a produção de ovos, conforme apresentado na tabela 05 . A criação animal é alicerçada nos rebanhos bovinos, caprinos, ovinos, suínos e nas aves.

A análise dos dados mostra que esses produtos são cultivados por uma porcentagem de estabelecimentos pouco expressiva em relação ao número total do município, diferentemente da criação de bovinos. Dessa forma, pode-se deduzir que, devido ao grande número de habitantes envolvidos no setor agropecuário, majoritariamente familiar, a diversificação nos estabelecimentos está pouco presente. Outra possibilidade seria a existência de muitos estabelecimentos sem cultivos ou criações. Porém, esta faceta é menos provável em razão de o número de munícipes envolvidos nessa atividade ser quase a metade do total.

Tabela 5 - Culturas exploradas, número de estabelecimentos em que estão presentes, porcentagem correspondente em relação ao total dos estabelecimentos existentes e renda média mensal referente às culturas exploradas por estabelecimento.

$$
\text { № de estabelecimentos com a exploração }
$$
das culturas

\begin{tabular}{|c|c|c|c|}
\hline \multirow[b]{2}{*}{ Cultura } & \multicolumn{2}{|c|}{ das culturas } & Renda Média N \\
\hline & Unidades & $\begin{array}{c}\text { Porcentual em relação } \\
\text { ao total }\end{array}$ & $\begin{array}{c}\text { por estabelecimento } \\
(\mathrm{R} \$)\end{array}$ \\
\hline
\end{tabular}
$(\%)$

\begin{tabular}{cccc}
\hline Milho & 690 & 22,7 & 399,50 \\
Feijão & 487 & 16 & 205,7 \\
Feijão fradinho & 441 & 14,5 & 78,8 \\
Mandioca & 218 & 7,2 & 112,77 \\
Cana de açúcar & 114 & 3,75 & 67,25 \\
Banana' & 5 & 0,17 & 283,00 \\
\hline
\end{tabular}

Fonte: Elaborado de acordo com os dados do Censo Agropecuário 2006. ${ }^{1}$ estabelecimentos que possuem mais de 50 pés de banana.

O Censo Agropecuário de 2006 mostrou que haviam sido comercializados 579 mil litros de leite, média mensal de 15,6 litros por estabelecimento. O município produziu 27 mil dúzias de ovos, mas apenas cinco mil foram comercializadas, média de 1,62 por estabelecimento/ano. Os rebanhos animais, que, à primeira vista, parecem ser em quantidade elevada, em média por estabelecimento são pouco expressivos e acabam por não conseguir alavancar a geração de renda e melhorias nas condições socioeconômicas dos agricultores locais. $\mathrm{Na}$ Tabela 06, são apresentadas as médias por estabelecimento.

Tabela 6 - Número total dos rebanhos, número de estabelecimentos criadores e média de cabeças por estabelecimento.

\begin{tabular}{cccc}
\hline Rebanhos & $\begin{array}{c}\text { Quantidade dos } \\
\text { rebanhos }\end{array}$ & $\begin{array}{c}\text { Estabelecimentos } \\
\text { criadores }\end{array}$ & $\begin{array}{c}\text { Média de cabeças } \\
\text { por } \\
\text { Estabelecimento }\end{array}$ \\
\hline Bovinos & 20.251 & 1.590 & 12,7 \\
Caprino & 8.910 & 438 & 20,3 \\
Ovino & 8.289 & 441 & 18,8 \\
Suínos & 5.139 & 967 & 5,31 \\
Aves & 29.000 & 1.710 & 16,9 \\
\hline
\end{tabular}

Fonte: Elaborado de acordo com os dados do Censo Agropecuário 2006. 
Portanto, face aos baixos rendimentos médios detectados, é notório o motivo da alta porcentagem de pessoas ligadas ao tema pobreza descrito pelo PNUD. A caracterização dos sistemas produtivos dos agricultores que comercializam via PNAE também será útil neste entendimento.

\subsection{Perspectivas dos agricultores familiares que acessam o PNAE sobre o programa e a caracterização dos seus sistemas produtivos}

A importância da caracterização dos sistemas produtivos é alicerçada na perspectiva trazida por Guanziroli et al. (2011). Segundo os autores, em investigações que envolvem o âmbito das políticas públicas, é extremamente importante identificar, analisar e descrever esses sistemas, haja vista que eles são adotados de acordo com os "contextos específicos de restrições e disponibilidade de recursos naturais, financeiros, tecnológicos, institucionais e humanos, com os quais se defrontam as várias regiões do país." (GUANZIROLI et al., 2011, p. 237). Dessa forma, a adoção dos sistemas produtivos está intimamente relacionada ao desenvolvimento e à situação socioeconômica dos agricultores.

Assim, no intuito de entender a realidade produtiva dos agricultores familiares e sua relação com o PNAE em Boquira, buscou-se construir um retrato dos modos de reprodução e dos seus sistemas produtivos. A identificação das ocorrências descritas pelo Censo Agropecuário 2006 e por Souza Filho et al. (2004), consideradas relevantes para identificar a heterogeneidade da agricultura familiar, foi utilizada como baliza na produção dos questionários. Assim, os questionamentos aplicados aos agricultores familiares boquirenses estão além das operações de comercialização em âmbito do PNAE.

Dos dez agricultores familiares que comercializam para a merenda escolar em Boquira, nove participaram da pesquisa (90\%). Todos afirmaram residir no estabelecimento onde cultivam; oito são proprietários do estabelecimento, apenas um agricultor é parente do proprietário; todos os estabelecimentos têm energia elétrica, mas apenas para uso residencial; e 55,6\% têm água encanada.

Em relação aos serviços de Ater, três agricultores disseram ter acesso a eles. Desses, um diz que a nutricionista da Secretaria Municipal de Educação colabora com orientações referentes à higiene dos produtos. Os outros dois dizem receber assistência técnica voltada para a produção primária. Um relatou que essa assistência é prestada pela Secretaria Municipal de Agricultura em visitas mensais; o outro diz receber orientação de um técnico ligado à associação, quando há reunião nessa instituição.

No tocante à utilização de adubos e práticas de conservação dos solos, quatro agricultores afirmam usar em seus cultivos adubos orgânicos (restos de culturas, esterco etc.), o que na prática é considerado também técnica de conservação. Adubos químicos e agrotóxicos não são utilizados pelos agricultores familiares, nem sementes melhoradas, suplementos minerais, vacinas, rações compradas (milho, torta de algodão, feno etc.). Apenas um dos agricultores faz controle de pragas, utilizando fumo e caldo de pimenta, técnica agroecológica, e apenas um diz produzir rações para alimentação animal.

Máquinas e equipamentos agrícolas não são utilizados por nenhum dos agricultores entrevistados, assim, a mecanização não é aplicada como tipo de força nos trabalhos. Sistemas de irrigação também não são utilizados nos estabelecimentos. 
Todos consideram que nos últimos cinco anos a estiagem prejudicou as atividades agrícolas, porém, a maioria deles, $66,7 \%$, declarou não ter tomado nenhuma providência para reduzir as perdas. Os demais afirmaram ter contratado carro pipa para amenizar o problema.

Assim, a seca e a inexistência de sistemas de irrigação afetam diretamente a produção primária do município. Apenas três agricultores comercializaram produtos in natura como couve, tempero verde, cenoura, batata doce, banana, laranja e abobora. Consequentemente, isso explica a maior preferência por produtos processados, como, por exemplo, avoador, biscoito de tapioca, brevidade e pão caseiro, comercializados por seis agricultores; a maioria desses produtos deriva da mandioca, cultura que apresenta alta resistência à escassez hídrica.

Na educação, o nível de instrução é diversificado. Dois não sabem ler e escrever; três têm o ensino fundamental incompleto; três, o nível médio completo; e um está cursando o ensino superior.

O financiamento para a produção nunca foi utilizado por $55,6 \%$ desses agricultores. Isso confirma a baixa porcentagem de financiamentos da agricultura familiar baiana apresentada na Tabela 02 e a afirmação de Guanziroli et al. (2011), quando os autores sinalizam que o financiamento para investimento utilizado pela agricultura familiar do nordeste é diminuto se comparado com as Regiões Sudeste e Sul.

Perguntados se têm outra fonte de recursos financeiros além da agricultura, os agricultores familiares entrevistados citam, com menor expressividade, a contribuição de familiares com trabalhos não relacionados ao setor agropecuário e a contribuição advinda da aposentadoria. No entanto, a maioria, declara que além da agricultura possuem como outras fontes de renda apenas programas especiais do governo federal $(55,6 \%)$. Certamente, isso colabora para o expressivo número de estabelecimentos da agricultura familiar baiana beneficiados com esses programas, cerca de $18 \%$ conforme exposto na tabela 04.

Cinco agricultores têm perspectiva de aumentar a produção em razão da comercialização via PNAE; quatro deles consideram que essa comercialização possibilitou a abertura ou a ampliação do mercado para seus produtos; e todos os cinco declaram ter outros canais de comercialização que não o PNAE.

Indagados se consideram que a comercialização via PNAE precisa ter algum tipo de mudança, todos disseram que sim. Como sugestões, foram levantadas as seguintes opiniões pelos entrevistados: "o pagamento precisa ser feito em dia" (2); "os preços pagos precisam aumentar" (2); "o transporte deveria ser por conta do município e a prefeitura deveria aumentar a quantidade e a variedade dos produtos adquiridos" (1); "a prefeitura deveria aumentar a quantidade dos produtos comprados" (1); "nós deveríamos ter acesso ao financiamento" (1); "nós deveríamos ter acesso ao financiamento, e o pagamento deveria ser feito em dia" (1); e "a prefeitura deveria aumentar a variedade para os produtos comprados" (1).

Perguntados sobre quais alternativas seriam necessárias para fortalecer a comercialização para que a agricultura familiar local se desenvolvesse, foram apresentadas no questionário diversas opções como: ter acesso ao financiamento; diversificar a produção; incentivar o artesanato; fortalecer 0 associativismo; desenvolver atividades turísticas; melhorar a educação; ter disponibilizados serviços de Ater contínuos e de qualidade (seguindo a orientação da PNATER); e desenvolver a infraestrutura (eletricidade, água, estradas etc.). Entre essas alternativas, a melhoria no setor educacional foi escolhida com unanimidade, 
seguida pela melhoria na infraestrutura, pelo fortalecimento da comercialização e pelos serviços de Ater.

\subsection{A perspectiva dos gestores municipais sobre o PNAE}

Os dois servidores municipais entrevistados, o secretário de educação e a nutricionista responsável por elaborar os cardápios da merenda escolar, enfatizaram a importância do programa para o município, tanto pela perspectiva da inserção dos agricultores familiares ao mercado quanto pela oportunidade de ofertar alimentos considerados saudáveis para os estudantes.

Segundo informações do secretário, Boquira tem 4.037 estudantes com acesso à alimentação escolar, destes, 3.952 recebem merenda e 85 alunos são beneficiados tanto pela merenda quanto pelo almoço. Apesar de ter 2.914 estabelecimentos da agricultura familiar, segundo os dados do IBGE, o município de Boquira conta com apenas dez agricultores familiares comercializando para a merenda escolar, menos de $0,5 \%$. Do recurso financeiro repassado no ano de 2013 pelo FNDE, aproximadamente $9,4 \%$ foi utilizado para a compra de alimentos da agricultura familiar. De acordo com os gestores, isto ocorre devido a pouca oferta de produtos no município, principalmente em razão da estiagem que assola a região. É ressaltado pela nutricionista que o PNAE, sob a perspectiva de compra da agricultura familiar, é novo em Boquira; por essa razão, desconhecido por muitos agricultores, dificultando assim o surgimento de interessados em acessar o programa.

Nesse aspecto, constatou-se que a Secretaria Municipal de Educação não desenvolve parcerias com instituições de Ater (Secretaria Municipal de Agricultura, Empresa Baiana de Desenvolvimento Agrícola - EBDA, ou outros). De acordo com o secretário, há interesse no estabelecimento de parcerias para o futuro.

Os gestores do PNAE em Boquira declararam que também há interesse em aumentar a compra de produtos da agricultura familiar municipal e adaptar o cardápio a essa produção. Isso inclui a inserção de novos gêneros no cardápio escolar, com a finalidade de diversificar a oferta de alimentos sem uso de agrotóxicos. Dessa forma, acreditam estar beneficiando os estudantes, por contribuir com a segurança alimentar do alunado e com os agricultores familiares locais, possibilitando inclusão social, redução do êxodo rural e da pobreza no município.

Porém, segundo eles, em Boquira não existe nenhum programa ou ação governamental que incentive ou apoie a produção primária e a instalação de agroindústrias de pequeno porte, a não ser o próprio PNAE. Para eles, mais iniciativas seriam essenciais para propiciar o beneficiamento de produtos locais, de modo a aumentar a oferta de alimentos para aquisição pelo programa em questão. Nesse aspecto, no intuito de maximizar a eficiência da agricultura familiar, a nutricionista relata que a gestão municipal pretende regionalizar os cardápios das escolas. Para identificar os hábitos alimentares locais, eles realizaram reuniões com os agricultores familiares para conhecer o perfil produtivo de cada comunidade e, assim, adaptar, da melhor forma possível, esses cardápios.

Ambos os entrevistados relatam que a Secretaria Municipal de Educação promove capacitações para as cozinheiras das escolas - conhecidas como merendeiras - e para os agricultores. As merendeiras receberam capacitação relacionada aos seguintes temas: boas práticas na manipulação de alimentos; técnicas de preparo para evitar doenças transmitidas por alimentos contaminados; 
elaboração de cardápios; e regras de higiene pessoal, do ambiente, dos utensílios e dos alimentos. Os agricultores foram orientados quanto aos aspectos abordados na legislação, como proceder com a entrega, embalagens, lotes, peso ou quantidade do produto.

O secretário municipal relata que, apesar de ter solicitado, não têm sido feitas fiscalizações pela vigilância sanitária nos locais de beneficiamento. Por esse motivo, a Secretaria Municipal de Educação e o Conselho de Alimentação Escolar promovem visitas aos agricultores no intuito de averiguar a higiene dos locais onde estas atividades são desenvolvidas. Porém, essas visitas são consideradas por ele como sendo pontuais e insuficientes diante das exigências de fiscalização sanitária no tocante à higienização dos produtos a serem comercializados para o programa. Ainda, de acordo com o secretário, quando o setor responsável pela merenda promove levantamento com os alunos, eles dizem gostar e avaliam de forma positiva 0 incremento de gêneros alimentícios da agricultura familiar local na merenda. Em breve, a Secretaria pretende promover degustações para avaliar a aceitabilidade.

Por fim, apesar das dificuldades descritas pelos gestores para a operacionalização do PNAE em Boquira, ambos consideram o programa uma política pública de relevância para o município, sobretudo, com um diagnóstico otimista em relação ao futuro, nesse caso, com a ampliação da compra de produtos de origem da agricultura familiar local.

\section{CONSIDERAÇÕES FINAIS}

O município de Boquira tem na agropecuária a principal atividade econômica para a maioria de suas famílias. A porcentagem de estabelecimentos familiares é maior do que a média baiana, atingindo 95,8\%. Porém, os agricultores de Boquira beneficiados pelo PNAE têm pouco acesso às tecnologias, aos serviços e às políticas públicas voltadas para o setor, a exemplo da Política Nacional de Assistência Técnica e Extensão Rural (PNATER) e do Programa Nacional de Fortalecimento da Agricultura Familiar (PRONAF), menos da metade dos agricultores entrevistados têm acesso aos financiamentos rurais e seus benefícios.

Ainda no que tange à PNATER, segundo o secretário municipal de educação, na época da pesquisa, em Boquira não existia escritório ou trabalhos da Empresa Baiana de Desenvolvimento Agrícola (EBDA) - principal instituição pública do estado da Bahia responsável pela prestação dos serviços de Ater para a agricultura familiar e, consequentemente, responsável pela implementação da PNATER.

Assim, a capacidade de inovar e/ou alterar os sistemas produtivos, de reformular as estratégias de trabalho, de diversificar a produção para agregar valor e renda e a possibilidade de ter acesso aos mercados estão pouco presentes em Boquira, fato que colabora para a existência da heterogeneidade da agricultura familiar brasileira.

Os agricultores de Boquira plantam em sequeiro, sofrem com a falta e a instabilidade das chuvas, comuns na região. Em seus sistemas produtivos, as técnicas de "convivência com semiárido"12 são pouco utilizadas. A Secretaria

\footnotetext{
12 Segundo Silva (2006) a "convivência com o semiárido" expressa uma nova percepção da complexidade que envolve a região semiárida. Deixa-se de lado a ideia de que a pobreza dessa região ocorre devido às características naturais e passa-se a buscar ou resgatar uma forma de vida em que a relação entre as pessoas, e dessas com a natureza, possa contribuir para a melhoria da qualidade de vida, e as atividades econômicas sejam apropriadas às características edafoclimáticas locais e busquem a sustentabilidade.
} 
Municipal de Educação não tem parceria com instituições de Ater, fato que evidencia que o arranjo institucional ofertado pela prefeitura municipal ainda é incipiente, sendo necessários ajustes e construções de parcerias com órgãos, a exemplo da própria EBDA, que possam colaborar para que os agricultores Boquirenses tenham mais acesso às políticas públicas existentes para o setor.

Face ao exposto e diante da questão inicial lançada nesse artigo, evidenciou-se que em Boquira pouco existe a potencialização dos sistemas produtivos primários, como também é incipiente aos agricultores familiares o acesso aos diversos recursos existentes no país, fato que também colabora com a existência da heterogeneidade desse setor no Brasil. Além disso, a produção primária em Boquira não consegue atingir a continuidade e a diversificação necessária para a potencialização da comercialização via PNAE.

A pobreza no município, refletida em estabelecimentos beneficiários dos programas especiais dos governos, segue a do estado. Dos agricultores que estão comercializando via PNAE, 66,7\% são atendidos por programas que complementam a renda familiar. No município, existem 7.807 domicílios, desses, 3.427 são contemplados com o programa Bolsa Família, 43,9\% (SEI, 2011).

O Programa Nacional de Alimentação Escolar (PNAE) efetivamente não é, atualmente, alternativa de expressão para a comercialização da agricultura familiar em Boquira, visto que apenas $0,5 \%$ dos agricultores familiares locais acessam o programa. Os recursos aplicados para a compra de alimentos oriundos da agricultura familiar também são pouco expressivos, tendo atingido, em 2013, menos de $10 \%$, contrariando a recomendação da lei $\mathrm{n} \times 11.947$, de 2009 , que estipula que 0 mínimo da aplicação dos recursos repassados pelo FNDE para a compra de alimentos oriundos da agricultura familiar seja de $30 \%$.

O PNAE, sob a perspectiva de compra da agricultura familiar, é considerado pelos gestores municipais do programa novo em Boquira. Segundo o secretário municipal de educação, apenas na atual gestão a prefeitura municipal de Boquira passou a adquirir produtos da agricultura familiar do próprio município. Antes, esse comércio era feito, na sua maioria, por atravessadores.

Face ao exposto, a agricultura familiar praticada nos estabelecimentos em Boquira ainda pode ser considerada de autoconsumo, com a venda do excedente, não existindo o dinamismo da agricultura familiar, conforme elucidam Guanziroli et al. (2011) ao relatarem a importância das adaptações dos sistemas produtivos com vistas à inserção no mercado e, consequentemente, à melhoria socioeconômica das famílias dos agricultores.

\section{REFERÊNCIAS BIBLIOGRÁFICAS}

ANJOS, F. S. CALDAS, N. V. Controle social e políticas públicas no espaço rural brasileiro. In. Pedrini, D. M.; Adams, T.; Silva, V. R. (Orgs.) Controle social de políticas públicas: caminhos descobertas e desafios. São Paulo: Paulus, 2007. p.151-177.

BRASIL. Lei no 11.947 de 16 de junho de 2009. Dispõe sobre o atendimento da alimentação escolar e do Programa Dinheiro Direto na Escola aos alunos da educação básica. Disponível em:

http://www.fnde.gov.br/fnde/legislacao/leis/item/3345-lei-n\%C2\%BA-11947-de-16-dejunho-de-2009. 
DIAS, R., MATOS, F. Políticas Públicas: princípios, propósitos e processos. São Paulo: Atlas, 2012. 252 p.

FLEXOR, G. \& LEITE, S. P. Análise De Políticas Públicas: Breves Considerações Teórico-Metodológicas. Disponível em:

http://franciscoqueiroz.com.br/portal/phocadownload/gestao/AnalisePolitica\%20Publi ca_flexor_leite.pdf.

GUANZIROLI, C. E.; SABBATO, A.; VIDAL, M. F. Agricultura Familiar no Nordeste: uma análise comparativa entre dois censos agropecuários. Fortaleza. Banco do Nordeste, 2011. 172p.

GUILHOTO, J. J. M.; AZZONI, C. R.; ICHIHARA, S. M. A participação da agricultura familiar no PIB do Nordeste. Fortaleza, Banco do Nordeste do Brasil, 2012, $208 \mathrm{p}$.

MALUF, R. S. Alimentação, escola e agricultura familiar. R. Janeiro, OPPA/UFRRJ, 2009. Boletim 026; disponível em:

http://oppa.net.br/artigos/portugues/artigo_OPPA_br_026-05_2009-

renato_maluf.pdf. Acesso em 12 de fevereiro de 2014.

MINISTÉRIO DO DESENVOLVIMENTO AGRÁRIO. Agricultura familiar no Brasil e o "Censo Agropecuário 2006". Cartilha. 14 p. 2010. Disponível em:

http://sistemas.mda.gov.br/arquivos/2246122356.pdf. Acesso em 10 de março de 2014.

PEIXINHO, A. M. L.; A trajetória do Programa Nacional de Alimentação Escolar no período de 2003-2010: o relato do gestor nacional. Ciência e Saúde Coletiva. Rio de Janeiro. vol. 18. n. 4. p. 909-916. 2013.

PNUD. Programa das Nações Unidas para o Desenvolvimento. Atlas do Desenvolvimento Humano no Brasil, 2013. Disponível em: http://www.pnud.org.br. Acesso em: 19 de dezembro de 2013.

INSTITUTO BRASILEIRO DE GEOGRAFIA E ESTATÍSTICA - IBGE. "Censo Agropecuário 2006". Disponível em: ftp://ftp.ibge.gov.br/Censos/Censo_Agropecuario_2006/agri_familiar_2006/.

REAL, L. C. V.; SCHNEIDER, S. O uso de programas públicos de alimentação na reaproximação do pequeno produtor com o consumidor: o caso do programa de alimentação escolar. Estudo e debate. Lajeado. v. 18, n. 2, p.57-59, 2011. Disponível em: http://www.univates.br/revistas/index.php/estudoedebate/search/results.

SARAIVA, E. B.; SILVA, A. P. F.; SOUZA, A. A.; CERQUEIRA, G. F.; CHAGAS, C. M. S. TORAL, N. Panorama da compra de alimentos da agricultura familiar para o Programa Nacional de Alimentação Escolar. Ciência e Saúde Coletiva. Rio de Janeiro. v. 18. n. 4. p. 927-939. 2013. 
SEI - Superintendência de Estudos Econômicos e Sociais da Bahia. Estatística dos municípios baianos. Salvador: 2011. v. 19; 182 p.

SECCHI, L. Políticas públicas: conceitos, esquemas de análises, casos práticos. São Paulo Cengage Learning, 2010. 133 p.

SCHNEIDER, S.; NIERDELE, P. A. Agricultura familiar e teoria social: a diversidade das formas familiares na agricultura. In: FALEIRO, F. G.; FARIAS NETO, A. L. (Ed.). Savanas: desafios e estratégias para o equilíbrio entre sociedade, agronegócio e recursos naturais. Planaltina, D. F., Embrapa Cerrados, 2008, p. 989 1014.

SILVA, R. M. A.; Entre o combate a seca e a convivência com o semiárido: Transições paradigmáticas e sustentabilidade do desenvolvimento. Tese de doutorado. Centro de Desenvolvimento Sustentável. Universidade de Brasília- UNB. 2006, 298 p.

SOUZA FILHO, H.M.; BUAINAIN, A. M.; GUANZIROLI, C. Agricultura Familiar e Tecnologia no Brasil: características, desafios e obstáculos. CONGRESSO DA SOBER. 2004, Cuiabá. Disponível em: http://ceragro.iica.int/Documents/Sober_2004_Souza_F_Buainain_Guanziroli[1].pdf.

SOUZA, C. Estado do campo da pesquisa em políticas públicas no Brasil. In. HOCHMAN, Gilberto et al. (Orgs.). Políticas públicas no Brasil. Rio de Janeiro: Editora Fiocruz, 2007. p 65-86.

STEIN, E.; TOMMASI, M. Para compreender a política das políticas públicas: uma abordagem metodológica. In: STEIN, E. et al. A política das políticas públicas. p 11-22, 2006a. As instituições políticas, o funcionamento do sistema de formulação de políticas e os resultados das políticas. In: STEIN, E. et al. A política das políticas públicas. p. 129-154, 2006b.

TONNEAU, J. P. \& SABOURIN, E. (Org.). Agricultura familiar, políticas públicas e dinâmicas locais. Porto Alegre: Ed. UFRGS, 2006. 323p.

TURPIN, M.E. A Alimentação Escolar como Fator de Desenvolvimento Local por meio do Apoio aos Agricultores Familiares. Segurança Alimentar Nutricional. Campinas. V. 16, n. 2 p.20-42. Disponível em:

http://www.unicamp.br/nepa/arquivo_san/volume_16_2_2009/2_Marina_MariaElena Turpin\%5B20-42\%5D.pdf. Perspectivas de la agricultura y del desarrolho rural em las Américas: uma mirada hacia América Latina y el Caribe. IICA. Sede Central, San José, Costa Rica. 2014. 62 p. Disponível em: http://repiica.iica.int/docs/b3165e/b3165e.pdf. 